Shih-Cheng Chen • Hui-Wen Liu • Kung-Ta Lee •

Takashi Yamakawa

\title{
High-efficiency Agrobacterium rhizogenes-mediated transformation of heat inducible sHSP18.2-GUS in Nicotiana tabacum
}

Received: 13 November 2005 / Revised: 18 April 2006 / Accepted: 2 May 2006 / Published online: 28 July 2006

(C) Springer-Verlag 2006

\begin{abstract}
The chimerical gene, Arabidopsis thaliana sHSP18.2 promoter fused to E. coli gusA gene, was Agrobacterium rhizogenes-mediated transformed into Nicotiana tabacum as a heat-regulatable model, and the thermo-inducible expression of GUS activity in $N$. tabacum transgenic hairy roots was profiled. An activation of A. rhizogenes with acetosyringone (AS) before cocultured with tobacco's leaf disc strongly promoted transgenic hairy roots formation. Transgenic hairy roots formation efficiency of $A$. rhizogenes precultured with $200 \mu \mathrm{M}$ AS supplementation was 3.1-fold and 7.5-fold, respectively, compared to the formation efficiency obtained with and without AS supplementation in coculture. Transgenic hairy roots transformed with different AS concentration exhibited a similar pattern of thermo-inducibility after $10 \mathrm{~min}$ to $3 \mathrm{~h}$ heat treatments detected by GUS expression. The peak of expressed GUS specific activity, 399,530 pmol MUG per mg total protein per min, of the transgenic hairy roots was observed at $48 \mathrm{~h}$ after $3 \mathrm{~h}$ of $42^{\circ} \mathrm{C}$ heat treatment, and the expressed GUS specific activity was 7-26 times more than that reported in A. thaliana, tobacco BY-2 cells and Nicotiana plumbagini-
\end{abstract}

Communicated by I. Chung

S.-C. Chen · H.-W. Liu · K.-T. Lee $(\bowtie)$

Graduate Institute of Microbiology and Biochemistry,

National Taiwan University,

1, Sec. 4, Roosevelt Road, Taipei, Taiwan

e-mail: ktlee@ntu.edu.tw

e-mail: b87603205@ntu.edu.tw

e-mail: r92b47103@ntu.edu.tw

Tel.: +886-2-3366-4436

Fax: +886-2-2364096

T. Yamakawa

Department of Global Agricultural Sciences,

University of Tokyo,

Bunkyo-ku, Tokyo, Japan

e-mail: ayama@mail.ecc.u-tokyo.ac.jp

Present address:

S.-C. Chen

Division of Pharmacognosy, Section Metabolomics, Institute of Biology, University Leiden,

P.O. Box 9502, 2300 RA Leiden, The Netherlands folia. Interference caused by AS supplementation on the growth of transgenic hairy roots, time-course of GUS expression and its expression level were not observed.

Keywords Acetosyringone -Agrobacterium rhizogenes . Arabidopsis thaliana sHSP18.2 - Transgenic hairy roots

\section{Introduction}

In the past few decades, we have seen plant cell cultures established as chemical factories for secondary metabolites (Rao and Ravishankar 2002). However, as there is an increasing demand for recombinant proteins, plant cell cultures have been considered a potent system for an efficient production of recombinant proteins, providing an economical and safety-reliable supplement. Plant-derived proteins are generally considered as possessing complete conformation and posttranslational modification which are essential for most therapeutic proteins (Magnuson et al. 1996; Fischer et al. 1999; Hong et al. 2002; James et al. 2002; Su and Aris 2003). Furthermore, an ideal "protein factory", in a bioengineering sense, can be established by optimized unit of plant cell cultures.

To introduce foreign genes into the genome of plant cells, Agrobacterium-mediated transgenic assay has become the most crucial method. The efficient capability of integrating expressive cassette, within the T-DNA region, into plant genomes governs a high transformation efficiency of plant cells (Riva et al. 1998). Agrobacterium-mediated transformation results in fewer copies of transgene in the plant genome and potentially reduces the problems of transgene cosuppression and instability (Borsics et al. 2002; Cui and Ezura 2003).

However, the reported studies of applying A.rhizogenesmediated transformations for recombinant protein expression are much less on the shelf than those of utilizing $A$. tumefaciens-mediated transgenic strategies. Although the "hairy root syndrome" has been demonstrated for the $A$. rhizogenes-mediated transgenic plants in some cases, the 
altered phenotype may be applicable in other instances (Van de Velde et al. 2003). The advantages of Ri-plasmid-based transgenic plants include avoidance of the callus phase in spontaneous shoot regeneration, high transformation rate, and long-term regeneration capability (Giri and Narasu 2000). Moreover, A. rhizogenes-mediated roots possess stable regenerated ability after a long-term screening culture, and have a growth rate similar to the level of suspension cells (Shanks and Morgan 1999). However, most reports of A. rhizogenes-transformed root cultures relate to the production of secondary metabolites, such that the utilization of transformed roots for recombinant protein production is less reported (Doran 2000).

Acetosyringone, reported as a virulence inducer to Agrobacterium that promotes Agrobacterium-mediated infection of plant (Stachel et al. 1985; Stachel and Nester 1986), is widely used as an efficient enhancer for Agrobacterium-mediated plant transformation. A number of plant species and their mediating Agrobacterium, an exogenous supplement of AS has been reported applied via pretreating plant explant (Guivare'h et al. 1993; Sunikumar et al. 1999) or Agrobacterium culture (Gelvin and Liu 1994; James et al. 1993; Sheikholeslam and Weeks 1987). Moreover, by inclusion of the AS in the coculture medium (Godwin et al. 1991; Holford et al. 1992) and by combining the pretreatment of explant and Agrobacterium culture (Boase et al. 1998) had also been found to enhance the efficiency of Agrobacterium-mediated transformation.

The small heat shock proteins (sHSP) are of unusual abundance and diversity in prokaryotic and eukaryotic cells under heat stress (Sun et al. 2002). Their physiological roles mainly appear to increase thermo-tolerance to sHSPexpressed plants (Lee et al. 1995; Prändl et al. 1998), although sHSP expression is also detectable during developmental seeding (Wehmeyer and Vierling 2000; Tada et al. 2003) and ripening (Ramakrishna et al. 2003). The expression of the Arabidopsis HSP18.2-GUS gene has been reported in cultured transgenic $N$. tabaccum BY-2 cells (Yoshida et al. 1995) and in transgenic N. plumbaginifolia (Moriwaki et al. 1999a, 1999b, 1999c). Hairy root cultures are considered to be superior to suspension cell cultures in genetic and biochemical stability. Doran (2000) reported that the previous study (Sharp and Doran 1999) has shown that recombinant protein levels are significantly higher in hairy roots than in plant cell suspensions. The promoter of Arabidopsis thaliana small heat shock protein 18.2 (Takahashi et al. 1992) was introduced in this study to establish and investigate the inducible expression of GUS activity in transgenic tobacco hairy root cultures.

\section{Materials and methods}

Plasmid construction and A. rhizogenes transformation

The DNA fragment of small heat shock protein 18.2 (sHSP18.2), which contains heat-shock-factor (HSF)binding domains and promoter region, was originally isolated from Arabidopsis thaliana genomic DNA (Takahashi et al. 1992). The genomic DNA fragment which includes 77 bp of sHSP18.2 coding sequence was subsequently introduced in-frame upstream to the $E$. coli gusA reporter gene in binary vector pBI101.2. Thus, the complete fusion of sHSP18.2 promoter and bacterial gusA gene in binary vector pBI101.2 is named pHS/GUS. After confirming the sequences of fused fragment of sHSP18.2 promoter and gusA gene, the plasmid pHS/GUS was transformed into the plasmid carrier host, E.coli strain JM109.

Purified binary vector $\mathrm{pHS} / \mathrm{GUS}$ was prepared to transform Agrobacterium rhizogenes strain 1724 by electroporation (Mattanovich et al. 1989), and subsequently screened for kanamycin resistance. To confirm the inheritance of $\mathrm{pHS} / \mathrm{GUS}$ in A. rhizogenes, PCR was carried out using the specific primers 5'-ATGTTACGTCCTGTAGAAACCC$3^{\prime}$ and $5^{\prime}$-TCATTGTTTGCCTCCCTGCTG- ${ }^{\prime}$, in a $25 \mu \mathrm{l}$ reaction solution containing 1 ng DNA, $0.8 \mu \mathrm{M}$ dNTP each, 5U VioTaq polymerase (Viogene, http://www.viogene.com), with 35 cycles of $30 \mathrm{~s}$ at $94^{\circ} \mathrm{C}$, $1 \mathrm{~min}$ at $55^{\circ} \mathrm{C}$, and $2 \mathrm{~min}$ at $72^{\circ} \mathrm{C}$. The amplified DNA fragment was subjected to electrophoresis on a $1.2 \%$ agarose gel (data not shown).

Plant materials and transformation

Seeds of Nicotiana tabacum var. TT5 (native fluecurred tobacco var. Taiwan tobacco $5 ; \mathrm{P}_{2}$, wide oval leaf) were submerged in $0.5 \%(\mathrm{v} / \mathrm{v})$ solution of sodium hypochloride for $10 \mathrm{~min}$, before a surface sterilization by immersion into $75 \%(\mathrm{v} / \mathrm{v})$ ethanol for $30 \mathrm{~s}$. The sterilized seeds were then rinsed in double-distilled water. Seeds germinated at $25^{\circ} \mathrm{C}$ on medium consisting of $15 \mathrm{~g} \mathrm{l}^{-1}$ sucrose, half-strength inorganic salts, and vitamins of Murashige and Skoog's (MS) medium (Murashige and Skoog 1962), solidified in $7 \mathrm{~g}^{-1}$ agar. After germination, tobacco explants were transferred to culture boxes and allowed to grow in a controlled chamber in 50\% relative humidity and a $16 / 8 \mathrm{~h}$ (day/night) light cycle at $25^{\circ} \mathrm{C}$. Five-week-old leaf stalks of tobacco explants were used to carry out the downstream of $A$. rhizogenes-mediated transformation. A. rhizogenes harboring the modified binary vector $\mathrm{pHS} / \mathrm{GUS}$ was allowed to grow for $12 \mathrm{~h}$ at $37^{\circ} \mathrm{C}$ in SOB medium containing $100 \mu \mathrm{g} \mathrm{ml}^{-1}$ kanamycin, while the binary vector -lacking A. rhizogenes was grown in antibiotic-free SOB medium. Before executing A. rhizogenes-mediated transformation, A. rhizogenes were precultured at $37^{\circ} \mathrm{C}$ for $12 \mathrm{~h}$ on agar medium which contains half-strength MS and 0 , 200 , or $400 \mu \mathrm{M}$ of virulence activator, acetosyringone, respectively.

Subsequently, A. rhizogenes was applied to the cut edges of tobacco leaf discs (ca. $1 \mathrm{~cm}^{2}$ ) and the leaf discs were placed on a fresh half-strength MS agar medium containing 0,200 , and $400 \mu \mathrm{M}$ of $\mathrm{AS}$, and proceed to the coculture as well. This coculture continued for 4 days at $22^{\circ} \mathrm{C}$ in the dark. Cocultured leaf discs were then transferred to agar media without acetosyringone but containing $300 \mathrm{mg} \mathrm{l}^{-1}$ cefotaxime to facilitate the sterile-cultivation, which lasted 21 days at $27^{\circ} \mathrm{C}$. Every leaf disc was processed calculating 
the number of countable roots, while the standard deviation was derived from the results of 10-leaf discs and $t$-test was introduced between groups defined by different concentrations of AS. At the end of sterile culture, the transformed roots were picked and then transferred onto hormone-free, half-strength MS agar media containing $300 \mathrm{mg}^{-1}$ cefotaxime.

\section{Heat-stress treatment of transformed roots}

Sterile-transformed roots were further transferred and cultured in half-strength MS liquid media with $3 \%$ sucrose in an orbital shaker with $100 \mathrm{rpm}$ at $27^{\circ} \mathrm{C}$ in the dark. The inoculation was $50 \mathrm{mg}$ in a $250 \mathrm{ml}$ flask containing $50 \mathrm{ml}$ of halfstrength MS medium with $3 \%$ sucrose. Finally, 28 clones were obtained. Lasting for $10 \mathrm{~min}, 30 \mathrm{~min}$, or $3 \mathrm{~h}$ respectively, heat-shock treatments were subsequently applied to 21-day-old root cultures, carried out by a $42^{\circ} \mathrm{C}$ waterbath shaker with $100 \mathrm{rpm}$. To evaluate the heat-induced GUS activity, time-coursed samplings were taken and the GUS activity was measured during the recovery-culture that was carried on at $27^{\circ} \mathrm{C}$ right after given heat-shock treatment.

\section{Quantitative assay of GUS activity}

Hairy roots that underwent the designed heat stress were frozen by liquid nitrogen immediately. Subsequently, lyophilized tissues were extracted for total proteins by a homogenizer with the GUS extracting buffer solution $(50 \mathrm{mM}$ Na-PO4, $10 \mathrm{mM}$ DTT, $1 \mathrm{mM} \mathrm{Na}{ }_{2}$ EDTA, $0.1 \%$ Triton $\mathrm{X}-100, \mathrm{pH} 8.0$ at $\left.4^{\circ} \mathrm{C}\right)$. After centrifugation $(12,000 \times g$, $15 \mathrm{~min}, 4^{\circ} \mathrm{C}$ ), the supernatant was collected, and the total protein extract was used to analyze the activity of GUS based on the 4-methylumbelliferyl $\beta$-D-glucuronic acid (MUG) method (Jefferson et al. 1987). The reaction was carried out at $37^{\circ} \mathrm{C}$ for $30 \mathrm{~min}$ and then stopped by the addition of $100 \mu \mathrm{l}$ of $0.2 \mathrm{M} \mathrm{Na}_{2} \mathrm{CO}_{3}$. The reaction mixture was carried into $50 \mu \mathrm{l}$ of $1 \mathrm{mM}$ MUG solution consisting of 3-5 $\mu \mathrm{g}$ total proteins. Using a fluorometer (Hitachi F-2000, http://www.hitachi-hta.com), fluorescence was de- tected by an emission at a wavelength of $460 \mathrm{~nm}$ while an excitation of $360 \mathrm{~nm}$ was given. The concentration of total soluble proteins was measured by protein assay kit (BioRad, http://www.bio-rad.com) with bovine serum albumin (BSA) as the standard. Relative GUS activity was calculated for catalytic activity based on the same total soluble proteins among different root cultures.

\section{Results}

\section{A. rhizogenes-mediated transformation of tobacco}

During induction of transformed roots, every individual primary root was counted to evaluate the efficiency of root formation in groups defined by acetosyringone (AS) concentration. Activation of 200 and $400 \mu \mathrm{M}$ AS in preculture of $A$. rhizogenes, the transformed roots formed from the damaged edges of the tobacco leaf discs were observed on 4-day cocultures. This indicates that, AS contributes more crucial enhancement during preculture of A. rhizogenes than coculture period (Table 1). Preculture of $A$. rhizogenes with $200 \mu \mathrm{M}$ AS significantly enhanced the efficiency of the transformed root formation, however, that further enhancement was achieved when the activation concentration of AS was doubled $(400 \mu \mathrm{M})$ in the preculture was less convincing. We also observed that the groups treated with AS in both the preculture and coculture (i.e., 200-200 and 400-400) showed no elevated effect in transformed root induction, compared to the groups of 200-0 and 400-0 within 21 days (data not shown). According to the efficiency of transformed root formation, the effects were less pronounced when the AS was only supplied during coculture although the preculture was lasted for only $12 \mathrm{~h}$ while the coculture was lasted for 4 days, suggesting that activation of Agrobacterium with AS in preculture provides the major contribution to transformation efficiency. Moreover, similar efficiency was concluded in pHS/GUS inherited $A$. rhizogenes in terms of transformed root formation, compared to the efficiency of native $A$. rhizogenes 1724 (Table 2). This undetectable difference suggests the possession of pHS/GUS did not critically affect the transformation ability to $A$. rhizogenes.
Table 1 The effects of AS supplementation in preculture and in coculture on roots formation

\begin{tabular}{llll}
\hline & \multicolumn{4}{l}{ Time of sterile-culture (days) } \\
\cline { 2 - 4 } $\begin{array}{l}\text { The given AS concentration in preculture/ } \\
\text { coculture }(\mu \mathrm{M})\end{array}$ & 7 & 14 & 21 \\
\cline { 2 - 4 } & 0.00 & $0.38 \pm 0.20$ & $2.13 \pm 0.66 \mathrm{~A}^{*}$ \\
$200-0$ & $0.17 \pm 0.30$ & $2.83 \pm 0.93$ & $4.50 \pm 0.51 \mathrm{~B}$ \\
$0-200$ & 0.00 & $0.90 \pm 0.60$ & $2.50 \pm 0.44 \mathrm{~A}$ \\
$400-0$ & $0.42 \pm 0.19$ & $2.42 \pm 0.45$ & $5.17 \pm 0.94 \mathrm{~B}$ \\
$0-400$ & 0.00 & $1.13 \pm 0.58$ & $3.88 \pm 0.46 \mathrm{C}$ \\
\hline
\end{tabular}

Efficiencies were determined quantity of formed roots (roots/leaf disc (LD) \pm SD) at the edges of leaf discs. Ten-leaf discs were assessed. The AS was supplied either during preculture or coculture

${ }^{*}$ The 21-day data were grouped by $t$-test when the $p$-value was less than 0.05 among values marked by letters $\mathrm{A}, \mathrm{B}$, and $\mathrm{C}$ 
Table 2 Efficiency of transformed root induction

\begin{tabular}{lllll}
\hline & \multicolumn{4}{l}{ Time of sterile-culture (days) } \\
\cline { 3 - 5 } Strain & AS supplement $(\mu \mathrm{M})$ & 7 & 14 & 21 \\
\hline Native A. & 0 & $0.57 \pm 0.58$ & $1.62 \pm 0.66$ & $3.55 \pm 0.86 \mathrm{~A}^{*}$ \\
rhizogenes 1724 & 200 & $2.23 \pm 0.53$ & $4.84 \pm 0.70$ & $5.86 \pm 0.78 \mathrm{~B}$ \\
& 400 & $1.87 \pm 0.76$ & $4.82 \pm 0.91$ & $5.30 \pm 1.06 \mathrm{~B}$ \\
pHS/GUS & 0 & $0.13 \pm 0.22$ & $1.73 \pm 0.46$ & $3.13 \pm 0.94 \mathrm{~A}$ \\
possessing A. & & & & \\
rhizogenes 1724 & 200 & $1.35 \pm 0.34$ & $4.26 \pm 0.49$ & $5.63 \pm 0.83 \mathrm{~B}$ \\
& 400 & $1.63 \pm 0.67$ & $3.83 \pm 0.85$ & $5.87 \pm 1.21 \mathrm{~B}$ \\
\hline
\end{tabular}

Root formation stratified by concentration of virulence inducer, acetosyringone, and strain. Efficiencies were determined quantity of formed roots (roots/leaf disc (LD) \pm SD) at the edges of leaf discs. Ten leaf discs were counted. The AS was supplied during pre-culture of A. rhizogenes possessing pHS/GUS or native $\mathrm{Ri}$-plasmid only

*The 21-day data were grouped by $t$-test when the $p$-value was less than 0.001 between values marked by letters $\mathrm{A}$ and $\mathrm{B}$

Hairy root culture

Selecting randomly from 1,048 independent root clones after Agrobacterium removal, 48 transformed clones, including 20 wild A. rhizogenes-transformed clones and 28 HS/GUS carried clones were liquid cultured. Possession of the Ri-plasmid marker, rolC gene, was detected in the genome of all of the 48 randomly selected clones (data not shown). The typical features of A. rhizogenes-transformed roots, abundance of lateral branches, lack of geotaxis, and rapid growth, were noted in the liquid-cultured transgenic hairy root tissues. The accumulated biomass of a 21-day culture of the selected clones was evaluated (Fig. 1). Diversities of accumulated biomass were demonstrated between individual clones. The fresh weight of the accumulated biomass ranged from about 3,000 $\mathrm{mg}$ to less than $100 \mathrm{mg}$ in the 21-day cultures.
Analyzing the growth of the 48 selected clones, there were no distinguishable differences by comparing the wild A. rhizogenes-mediated transgenic hairy roots and HS/GUS transgenic hairy roots, in terms of their growth ability (Fig. 1). This suggests that, regardless of expressed NPT II for Kanamycin resistance, diversity of biomass accumulation of the transformed roots was not resulted from the insertion of sHSP18.2 promoter. Such results provide support to the potential application of sHSP promoter in terms of regulated expression of recombinant proteins, especially those reported for host toxicity, in plant cell cultures.

Although AS and its time point of supplements are key factors in efficiency transformation, the growth ability of transformed root tissues appeared to be unaffected by the utrilization of AS, inferring that the virulence genes' expression level of the transforming A. rhizogenes is not related to the growth of the transformed roots.
Fig. 1 Accumulated biomass of the transformed root cultures. Forty-eight clones were randomly and stratified selected. The growth was evaluated according to accumulated biomass in fresh weight after 21-day culture. Fifty milligrams of fresh transformed roots was inoculated. HSP/GUS transgenic clones: $0 \mathrm{HG}, 200$ $\mathrm{HG}$, and $400 \mathrm{HG}$; wild type of tobacco hairy roots: $0 \mathrm{~W}, 200$ $\mathrm{W}$, and $400 \mathrm{~W}$

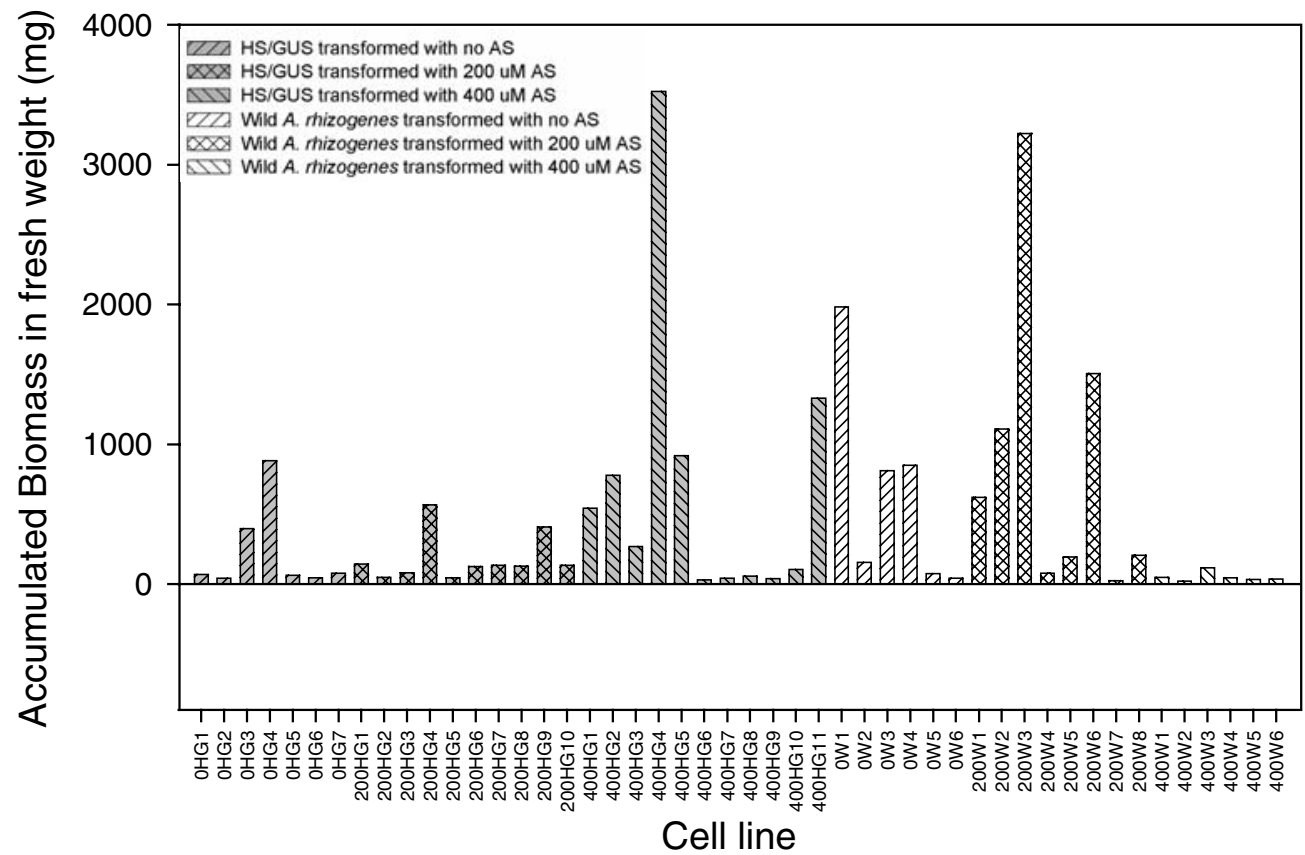


A.

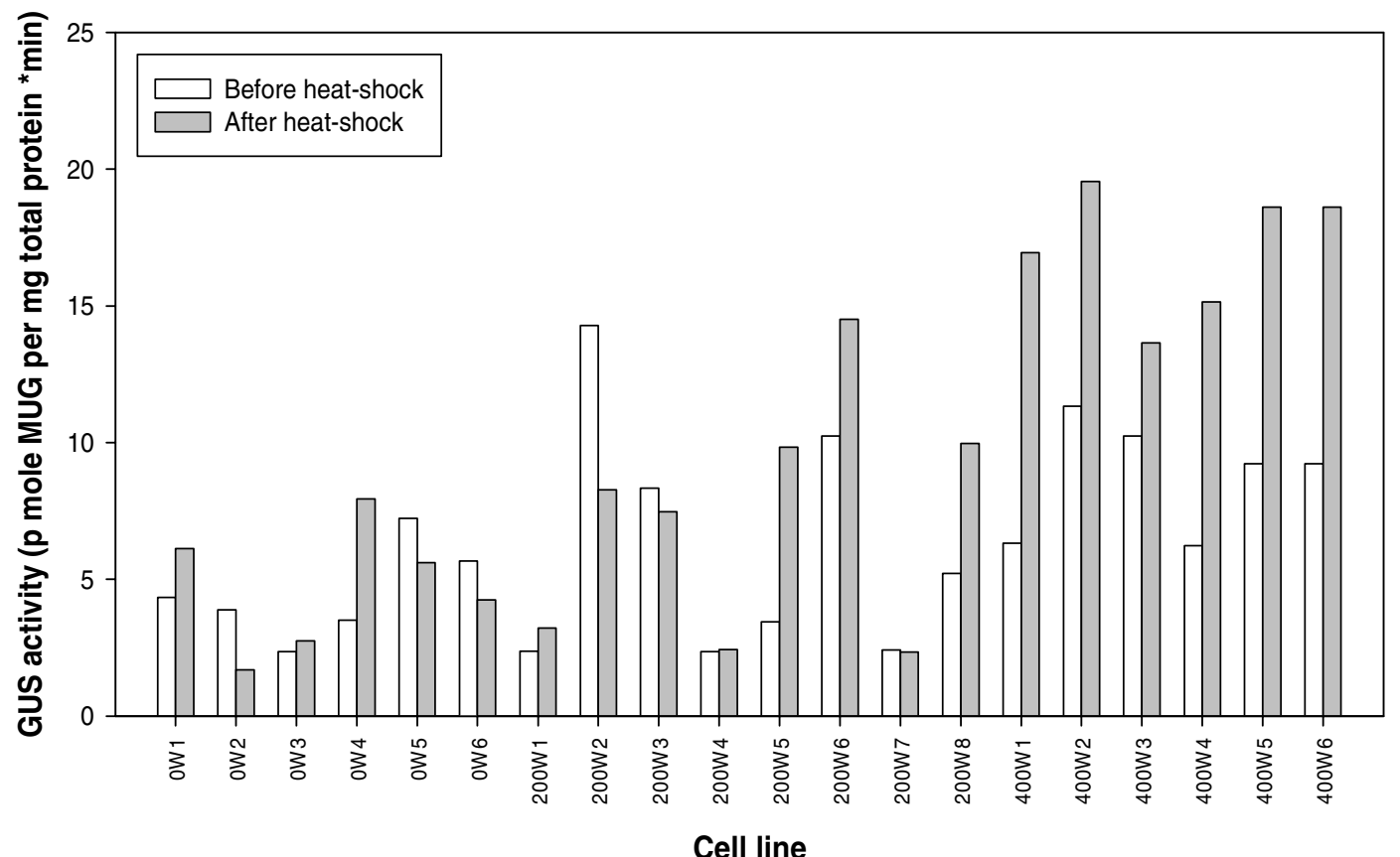

B.

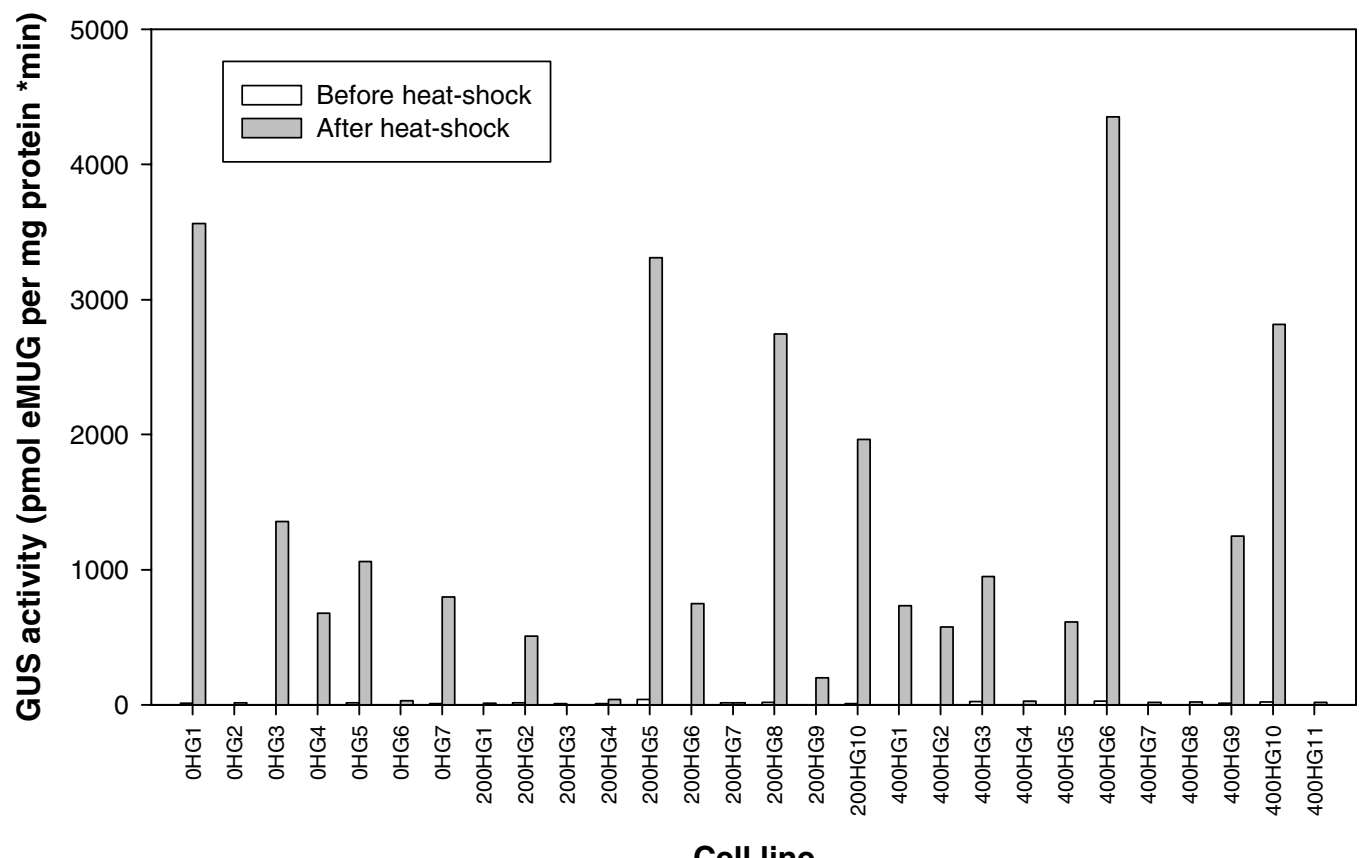

Fig. 2 Heat-inducible GUS activity of transgenic hairy roots. A Wild $A$. rhizogenes transformed roots. B pHS/GUS-possessing $A$. rhizogenes transformed roots. The heat-shock treatments were given

to 21-day cultures at $42^{\circ} \mathrm{C}$ for $3 \mathrm{~h}$; GUS activity was detected $4 \mathrm{~h}$ after the treatment. HSP/GUS transgenic clones: $0 \mathrm{HG}, 200 \mathrm{HG}$, and $400 \mathrm{HG}$; wild type of tobacco hairy roots: $0 \mathrm{~W}, 200 \mathrm{~W}$, and $400 \mathrm{~W}$

Heat-shock inducibility of transformed roots

All of the $28 \mathrm{HS} /$ GUS-transformed clones were detected as positive possession of the $\mathrm{Ri}$-plasmid marker, rolC gene, and the HS/GUS chimeric gene (data not shown). Treated by a given heat stress, the heat-shock-inducibility of GUS

activity in the sHSP18.2 promoter-possessing hairy roots was determined. The GUS activity of the liquid-cultured roots was detected after exposure to $42^{\circ} \mathrm{C}$ for $3 \mathrm{~h}$ (Fig. 2). Clearly, wild A. rhizogenes-transformed roots revealed extremely low heat-induced GUS specific activity (lower than $20 \mathrm{p}$ mole MUG per mg total protein per min) no matter 
Fig. 3 Thermo-sensibility of transformed roots: 21 -day cultures were exposed to heat shock at $42^{\circ} \mathrm{C}$ for various times. The means and standard deviations were shown according triplet experiments

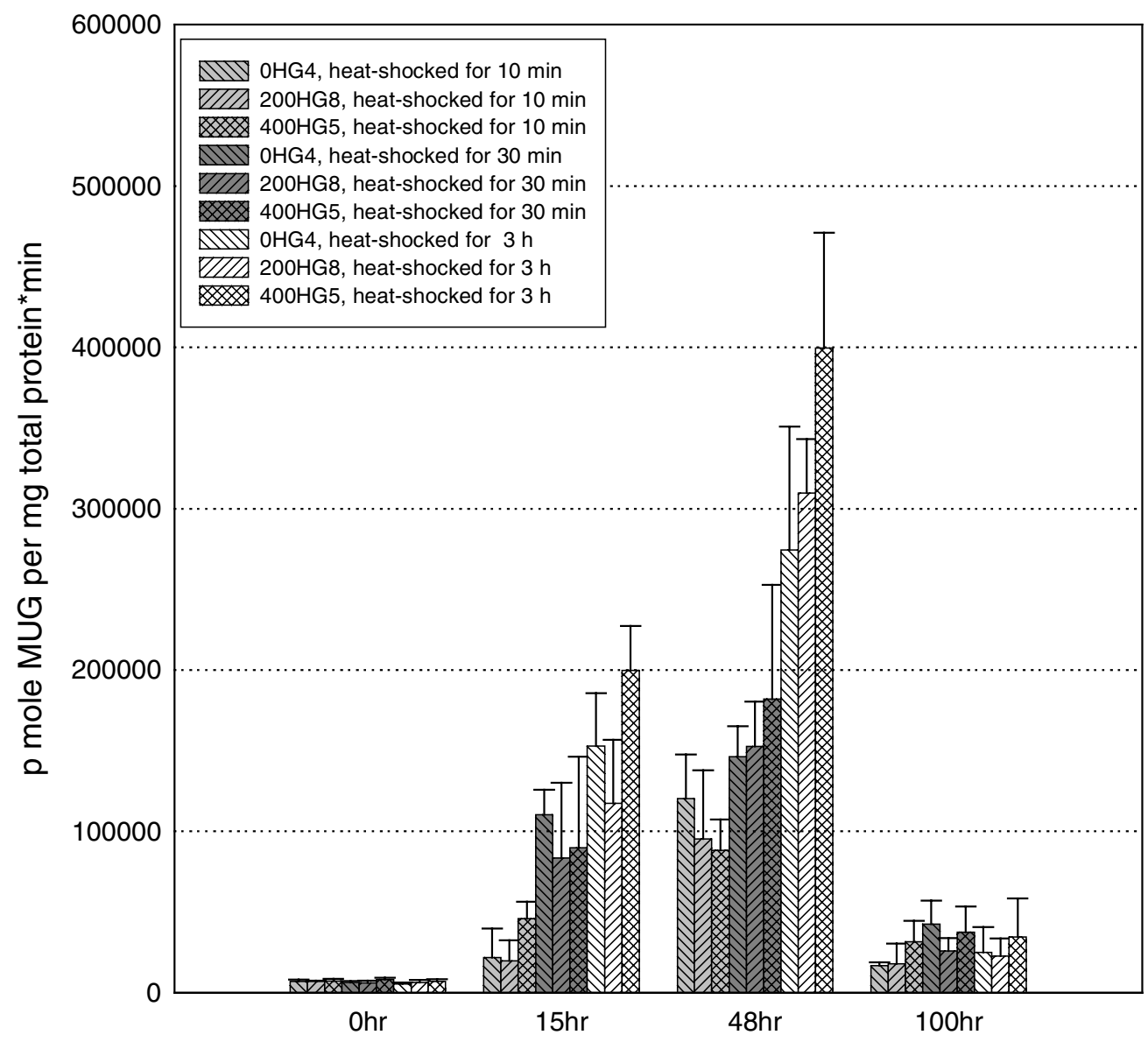

Time after heat-shock treatments before or after heat-shock treatment. In Fig. 2B, heat-shockinducible GUS activity was observed in 26 of the 28 selected transgenic HS/GUS clones, and the expressed GUS specific activity was most ranged from 500 to $4500 \mathrm{pmol}$ MUG per mg total protein per min, although all of these 28 clones present transgenic HS/GUS fragments in their genomes. In these data, we also realize that the utilization of AS in hairy root induction do not significantly interfere the co-transformation efficiency. Nevertheless, only background level of GUS activity was detected in two of the 28 HS/GUS-transformed clones (200HG1 and 200HG3), the heat-shock-inducibility was blocked in these two clones with unclear reasons.

Transgenic hairy roots, $0 \mathrm{HG} 4,200 \mathrm{HG} 8$ and 400HG5, which were transformed using 0,200 , and $400 \mu \mathrm{M} \mathrm{AS}-$ precultured $A$. rhizogenes, respectively, were subsequently evaluated for time-coursed inducible GUS activity by heatshock treatment at $42^{\circ} \mathrm{C}$ for $10 \mathrm{~min}, 30 \mathrm{~min}$, or $3 \mathrm{~h}$ (Fig. 3). The three clones were selected because of their higher heatinducible GUS productivity (Fig. 1 and Fig. 2B). The peak of expressed GUS specific activity was detected $48 \mathrm{~h}$ after heat-shock treatment, regardless of the exposure time in the heat-stress environment or the concentration of added AS when they underwent gene transformation. However, the 3-h treatment produced higher expression activity to the sHSP18.2 promoter compared to the $10 \mathrm{~min}$ analog, sug- gesting the expressing activity of sHSP promoter is timeof-exposure dependent.

\section{Discussion}

Many parameters related to Agrobacterium-mediated transformation efficiency have been studied in the past such as plant species, Agrobacterium strain, type of Ti/Ri plasmid, nature of binary vectors, and the size of the modified T-DNA. Transformation efficiency is though directly related to the activation of Agrobacterium vir genes (Riva et al. 1998) while the accumulation of wounding signals induces high vir gene expression. Moreover, acetosyringone and its relative compounds increase the capability for transformed cell formation (Baron et al. 2001; Joubert et al. 2002). However, so far no report directly demonstrates the impacts of AS-mediated enhancement on the transformed cells, although the AS has been widely used.

The previous study demonstrated that AS pre-incubation of tobacco leaf segments increases transformation efficiency and induces stronger expression of vir genes (Sunikumar et al. 1999). In our study, tremendous transformation capability was demonstrated for A. rhizogenes 1724 precultured with AS (Table 1). Compared to the AS-non- 
precultured A. rhizogenes, AS precultured A. rhizogenes was potent in terms of the transformation efficiency, suggesting that activation of Agrobacterium vir genes governed a highly efficient transformation. No noticeable improvement in transformed root formation was observed where AS was subsequently added to the coculture medium if the A. rhizogenes had been precultured with AS. This evidence, again, suggests AS induced more crucial effect in preculture of A. rhizogenes before coculture with leaf discs. Some explanations for the different effect of AS in preculture and coculture, in terms of the enhancement of transformation efficiency, are suggested as follows. (1) The endogenous wounding signals and delayed accumulation exogenous AS, which supplied in coculture media, contributes only minor improvement to transformation efficiency. The supplied AS in preculture of A. rhizogenes induces much stronger expression of vir genes. (2) The A. rhizogenes AS preculture guaranteed activation of the vir genes, and that the transformation was dominated by the readily expressed viral proteins (Engstorm et al. 1987). Thus, the whole T-DNA integrating mechanism is ready-assembled for AS precultured A. rhizogenes, which promotes the cellcell recognition and T-DNA transfer. (3) There implied an AS independent mechanism in the transformed root formation, which plays a crucial role in plant-Agrobacterium interaction. Preculture with AS might enable A. rhizogenes to escape from plant defensive actions against bacterial pathogens, or might be capable to transform the infected plant cells reduce activating effective defenses.

Furthermore, great co-transformation efficiency was noted among those 28 randomly selected root clones, all of them were detected possessions of transgene, HS/GUS. The co-transfer efficiency, which indicates the efficiency of transfering recombinant genes into the plant cell genome in parallel to the T-DNA of Ri-plasmid, should attract more attention during evaluation of the efficiency of the gene transformation. Compared to the previous reports for $A$. tumefaciens-mediated transformation of tobacco (Masoud et al. 1996; Tackaberry et al. 1999; Roger et al. 2001; Pandey et al. 2002), our results are remarkable in terms of both high transformation efficiency and great cotransfer efficiency of foreign genes. We assume that the pathogenic nature of the Ri-plasmid in A. rhizogenes strain 1724 may be partially responsible for the high cotransformation efficiency, although the detail mechanism behind is still poorly understood. However, notable diversities in growth rate imply uncertainty of Agrobacterium-mediated transformed roots, suggesting that a screening after cell transformation still plays a crucial role to obtain the highest productive cell line.

Moriwaki et al. (1999c) detected higher heat-induced GUS activity of sHSP18.2 promoter in root organs of transgenic $N$. plumbaginifolia explants, compared to other plant organs. This result supports that the A. rhizogenes transformed root cultures may be a better system compared to regenerated explants and undifferentiated suspension cells, in terms of high productivity. Indeed, the expressive productivity of sHSP18.2 promoter induced by heat stress was impressive in A. rhizogenes transformed $N$. tabacum roots. Compared to the previous investigations of transgenic A. thaliana (Takahashi et al. 1992), tobacco BY-2 cells (Yoshida et al. 1995) and N. plumbaginifolia (Moriwaki et al. 1999a), the expressive activity of the sHSP18.2 promoter in the $A$. rhizogenes-transformed roots was higher. Based on the same MUG-based quantitative procedures (Jefferson et al. 1987), the GUS specific activity in the $A$. rhizogenes-mediated transgenic root tissues was 7-26 times more than that reported for $A$. thaliana, tobacco BY-2 cells and N. plumbaginifolia. Our results suggest that, this different thermo-inducibility of sHSP18.2 promoter in N. tabacum refers to a root-specific heat-induced behavior. Different mechanism of heat stress-associated action to the sHSP18.2 promoter might be existed in root-differentiated tissues.

Currently, transgenic hairy roots are often developed by A. rhizogenes infection of leaf explants from highexpression transgenic plants. However, this is laborious and time-consuming. In this work, through a simple and direct transformation with A. rhizogenes, transgenic hairy root clones can be developed. Moreover, the regeneration of transgenic plant can be developed from the transgenic hairy root via a simple adjustment of media condition. Therefore, using direct $A$. rhizogenes-mediated transformation will be an efficient tool. Meanwhile, we examined the effects of AS in the process of A. rhizogenes-mediated transformation. The sHSP18.2 promoter exhibits an extraordinary strong thermo-induced activity in A. rhizogenes transformed roots. Such fundamental results not only revealed new signs to the studies of plant in heat stress but set up a great possibility to utilize hairy root cultures for an efficient expression of recombinant proteins.

Acknowledgements The authors are very grateful to Prof. Yoshibumi Komeda (Hokkaido University, Japan) for providing the HSP-18.2 gene (PTT119), to Prof. Kouichiro Shimomura (Tokyo University, Japan) for providing A. rhizogenes 1724, and to Dr. TzuHwie Liu (Development Center for Biotechnology, Taiwan) for her kindly provided tobacco seeds. This work was supported by a grant, 91-2313-B-002-358, from the National Science Council, ROC.

\section{References}

Baron C, Domke N, Beinhofer M, Hapfelmeier S (2001) Elevated temperature differentially affects virulence, VirB protein accumulation, and T-Pilus formation in different Agrobacterium tumefaciens and Agrobacterium vitis strains. J Bacteriol 183:6852-6861

Boase MR, Bradley JM, Borst NK (1998) An improved method for transformation of regal pelargonium (Pelargonium Xdomesticum Dubonnet) by Agrobacterium tumefaciens. Plant Sci 139:59-69

Borsics T, Mihálka V, Oreifig AS, Bárány I, Lados M, Nagy I, Jenes B, Toldi O (2002) Methods for genetic transformation of the parasitic weed dodder (Cuscuta trifolii Bab. et Gibs) and for PCR-based detection of early transformation events. Plant Sci 162:193-199

Cui M, Ezura H (2003) Agrobacterium-mediated transformation of Nemesia strumosa Benth, a model plant for asymmetric floral development. Plant Sci 165:863870

Doran PM (2000) Foreign protein production in plant tissue cultures. Curr Opin Biotechnol 11:199-204 
Engstorm P, Zambryski P, Montagu MV, Stachel S (1987) Characterization of Agrobacterium tumefaciens virulence proteins induced by the plant factor acetosyringone. J Mol Biol 197:635645

Fischer R, Liao Y, Drossard J (1999) Affinity-purification of a TMVspecific recombinant full-size antibody from a transgenic tobacco suspension culture. J Immunol Method 226:1-10

Gelvin SB, Liu CN (1994) Genetic manipulation of Agrobacterium tumefaciens strains to improve transformation of recalcitrant plant species. In: Gelvin SB, Schilperoort RA (eds) Plant Molecular biology manual. Kluwer Academic Publishers, Dordrecht, Netherlands, pp. B4/1-B4/13

Giri A, Narasu ML (2000) Agrobacterium rhizogenes-mediated transformation of Sesbania rostrata. Biotechnol Adv 18:1-22

Godwin I, Todd G, Ford-Lloyd B, Newbury HJ (1991) The effects of acetosyringone and $\mathrm{pH}$ on Agrobacterium-mediated transformation vary according to plant species. Plant Cell Rep 9:671675

Guivare'h A, Caissard JC, Brown S, Marie D, Dewitte W, Van Onekelen H, Chriqui D (1993) Localization of target cells and improvement of Agrobacterium-mediated transformation efficiency by direct acetosyringone pretreatment of carrot root discs. Protoplasma 174:10-18

Holford P, Hernandez N, Newbury HJ (1992) Factors influencing the efficiency of T-DNA transfer during co-cultivation of Antirrhinum majus with Agrobacterium tumefaciens. Plant Cell Rep 11:196-199

Hong S, Kwon T, Lee J, Jang Y, Yang M (2002) Production of biologically active hG-CSF by transgenic plant cell suspension culture. Enzyme Microb Technol 30:763-767

James DJ, Uratsu S, Cheng JS, Negri P, Viss P, Dandekar AM (1993) Acetosyringone and osmoprotectants like betaine or proline synergistically enhance Agrobacterium-mediated transformation of apple. Plant Cell Rep 12:559-563

James E, Mills DR, Lee JM (2002) Increased production and recovery of secreted foreign proteins from plant cell cultures using an affinity chromatography bioreactor. Biochem Eng J 12:205213

Jefferson RA, Kavanagh TA, Bevan MW (1987) GUS fusion: $\beta$ glucuronidase as a sensitive and versatile gene marker in higher plants. EMBO J 6:3901-3907

Joubert $\mathrm{P}$, Beaupère $\mathrm{D}$, Lelivère $\mathrm{P}$, Wadouachi $\mathrm{A}$, Sanhwan RS, Sangwan-Noeerrl BS (2002) Effects of phenolic compounds on Agrobacterium vir genes and gene transfer induction-a plausible molecular mechanism of phenol binding protein activation. Plant Sci 162:733-743

Lee JH, Hübel A, Schöffl F (1995) Derepression of the activity of genetically engineered heat shock factor causes constitutive synthesis of heat shock proteins and increased thermotolerance in transgenic Arabidopsis. Plant J 8:603-612

Magnuson NS, Linzmaier PM, Gao J, Reeves R, An G (1996) Enhanced recovery of secreted mammalian protein from suspension culture of genetically modified. Protein Expr Purif 7:220228

Masoud SA, Ding X, Johnson LB, White FF, Reeck GR (1996) Expression of a corn bifunctional inhibitor of serine proteinases and insect $\alpha$-amylases in transgenic tobacco plants. Plant Sci 115:59-69

Mattanovich D, Ruker F, da Camara Machado A, Laimer M, Regner F, Steinkellner H, Himmler G, Katinger H (1989) Efficient transformation of Agrobacterium spp. by electroporation. Nucleic Acids Res 17:6747

Moriwaki M, Yamakawa T, Washino T, Kodama T, Igarashi Y (1999a) A comparison of GUS activity after liquid- and air- heat shock treatment in transgenic Nicotiana plumbaginifolia harboring the Arabidopsis HSP18.2 promoter- GUS chimeric gene. Plant Biotechnol 16:303-305

Moriwaki M, Yamakawa T, Washino T, Kodama T, Igarashi Y (1999b) Suppressed phenylalanine ammonia-lyase activity after heat shock in transgenic Nicotiana plumbaginifolia containing an Arabidopsis HSP18.2-Parsley PAL2 chimera gene. J Biosci Bioeng 87:588-593
Moriwaki M, Yamakawa T, Washino T, Kodama T, Igarashi Y (1999c) Delayed recovery of $\beta$-glucuronidase activity driven by an Arabidopsis heat shock promoter in heat-stressed transgenic Nicotiana plumbaginifolia. Plant Cell Rep 19:96100

Murashige T, Skoog F (1962) A revised medium for rapid growth and bio assays with tobacco tissue cultures. Plant Physiol 15:473497

Pandey GK, Reddy VS, Reddy MK, Deswal R, Bhattacharya A, Sopory SK (2002) Transgenic tobacco expressing Entamoeba histolytica calcium binding protein exhibits enhanced growth and tolerance to salt stress. Plant Sci 162:41-47

Prändl R, Hinderhofer K, Eggers B, Schumacher G, Schöffl F (1998) HSF3, a new heat shock factor from Arabidopsis thaliana, derepresses the heat shock response and confers thermotolerance when overexpressed in transgenic plants. Mol Gen Genet 258:269-278

Ramakrishna W, Deng Z, Ding C, Handa AK, Ozminkowski RH (2003) A novel small heat shock protein gene, visl, constributes to pectin depolymerization and juice viscosity in tomato fruit. Plant Physiol 131:725-735

Rao SR, Ravishankar GA (2002) Plant cell cultures: Chemical factories of secondary metabolites. Biotech Adv 20:101153

Riva GA, González-Cabrera J, Vázquez-Padrón R, Ayra-Pardo C (1998) Agrobacterium tumefaciens: a natural tool for plant transformation. Electron J Biotechnol 1:118-133

Roger D, Lacoux J, Lamblin F, Gaillet D, Dauchel H, Klein D, Balangé AP, David A, Lainé E (2001) Isolation of a flax pectin methylesterase promoter and its expression in transgenic tobacco. Plant Sci 160:713-721

Sheikholeslam SN, Weeks PD (1987) Acetosyringone promotes high efficiency transformation of Arabidopsis thaliana explants by Agrobacterium tumefaciens. Plant Mol Biol 8:291298

Shanks JV, Morgan J (1999) Plant 'Hairy root' culture. Curr Opin Biotechnol 10:151-155

Sharp JM, Doran PM (1999) Effect of bacitracin on growth and monoclonal antibody production by tobacco hairy roots and cell suspensions. Biotechnol Bioprocess Eng 4:253-258

Stachel SE, Messens E, Van Montagu M, Zambryski P (1985) Identification of the signal molecules produced by wounded plant cells that activate T-DNA transfer in Agrobacterium tumefaciens. Nature 318:624-629

Stachel SE, Nester EW (1986) The genetic and transcriptional organization of the vir region of the A6 Ti plasmid of Agrobacterium tumefaciens. EMBO J 5:1445-1454

Su WW, Aris R (2003) Continous plant cell perfusion culture: bioreactor characterization and secreted enzyme production. J Biosci Bioeng 95:3-20

Sun W, Montagu M, Verbruggen N (2002) Small heat shock proteins and stress tolerance in plants. Biochim Biophy Acta 1577:1-

Sunikumar G, Vijayachandra K, Veluthambi K (1999) Preincubation of cut tobacco leaf explants promotes Agrobacteriummediated transformation by increasing vir gene induction. Plant Sci 141:51-58

Tackaberry ES, Dudant AK, Prior F, Tocchi M, Sardana R, Altosaar I, Ganz PR (1999) Development of biopharmaceuticals in plant expression systems: cloning, expression and immunological reactivity of human cytomegalovirus glycoprotein B (UL55) in seeds of transgenic tobacco. Vaccine 17:3020 3029

Tada Y, Wakasugi T, Nishikawa A, Furuhashi K, Yamada K (2003) Developmental regulation of grnr coding for a low-molecularweight heat shock protein during haustorium formation in the seedling of a holoparasitic plant, Cuscuta japonica. Plant Cell Physiol 41:1373-1380

Takahashi T, Naito S, Komeda Y (1992) The Arabidopsis HSP18.2 promoter/GUS gene fusion in transgenic Arabidopsis plants: a powerful tool for the isolation of regulatory mutants of the heatshock response. Plant J 2:751-761 
Van de Velde W, Mergeay J, Holsters M, Goormachtig S (2003) Agrobacterium rhizogenes-mediated transformation of Sesbania rostrata. Plant Sci 165:1281-1288

Wehmeyer N, Vierling E (2000) The expression of small heat shock proteins in seeds responds to discrete developmental signals and suggests a general protective role in desiccation tolerance. Plant Physiol 122:1099-1108
Yoshida K, Kasai T, Garcia MRC, Sawada S, Shoji T, Yamazaki S, Komeda Y, Shinmyo A (1995) Heat-inducible expression system for a foreign gene in cultured tobacco cells using the HSPI8.2 promoter of Arabidopsis thaliana. Appl Microbiol Biotechnol $44: 466-472$ 